\title{
Science for all
}

The Establishment of Science in America

by Sally Gregory Kohlstedt, Michael M. Sokal

and Bruce V. Lewenstein

Rutgers University Press · January 2000

Hardback $£ 29.50 / \$ 35$

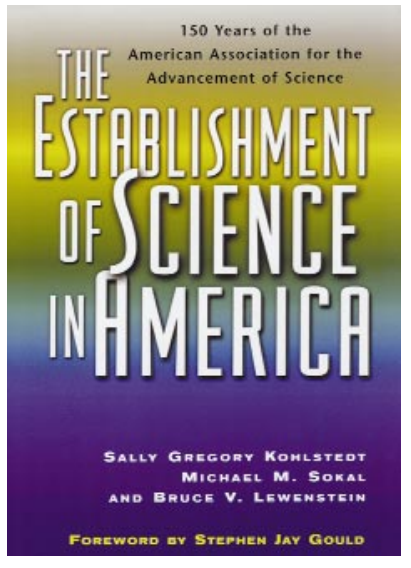

Andrew Aplin

... it has been a tightrope walk for the AAAS to promote of the scientific institution in the United States, one must consider the leading role of the American Association for the Advancement of Science (AAAS). This organization has been a cornerstone of science in the US since its inauguration in 1848. Here Kohlstedt, Sokal and Lewenstein provide an authoritative historical perspective of this society, from its humble beginnings in a Philadelphia library to the internationally recognized establishment of today. The authors enables the reader to appreciate how one facet of the US scientific community developed side by side with the evolution of a 'new world' nation. In three chapters, they chronicle successive half-century periods in the life of the association. The common thread in these chapters is the illumination of how the AAAS sought to fulfill its aim of promoting "the advancement of science and technology across all disciplines and to the public's understanding of these matters". At times it has been a tightrope walk for the AAAS to promote a delicate balance between pushing cuttingedge science while remaining within the realm of the general public. Occasionally, adhering to these objectives has required the AAAS to change direction to concur with changes in general society through the years.

Initially, Kohlstedt details the tribulations of the fledgling society and highlights the emphasis that the association placed on the proceedings of its annual meetings as the main forum for discussing new research breakthroughs. Covering the early 1900s, Sokal describes the beginning of the close relationship between the AAAS and the periodical Science, and the manner in which the AAAS served as an umbrella organization to encourage interdisciplinary dialogue as science became an increasingly specialized pursuit. This chapter deals largely with the apparently domineering role of James McKeen Cattell, owner and editor of Science between 1895

\section{a delicate balance between}

\section{pushing leading edge science}

while remaining within the

realm of the general public ...

and 1944, a subject on which Sokal has written several times. In the final chapter, Lewenstein tells how the AAAS found its niche in the post-war period and was at the forefront of dealing with contemporary issues. Furthermore, this era saw the popularization of science and the emergence of Science as a leading international journal. It is here that the reader develops an appreciation of how the AAAS was forced to grapple with the same issues that were shaping the nation as a whole - McCarthyism, racial segregation and anti-nuclear sentiment.

Each of the authors highlights the influential figures that steered and reshaped the AAAS during these periods. Special emphasis is placed throughout on illustrating the democratic ideals of society. However, one does not gain a sense of the relative influence that the AAAS has had on the development of the US scientific community in relation to other organizations, such as the National Academy of Sciences and the National Research Council. Nevertheless, careful attention is paid to the methods used by the AAAS in crossing disciplinary boundaries and in its 'reachout' programs, designed to enhance communication to a broader audience including the younger generation, women and minorities.

This book is both enjoyable and illuminating, and can be recommended to a wider readership than science historians alone. As the authors do not delve into the technical depths of scientific matters, it is easily accessible to students and professors alike. Furthermore, the book is of interest to readers outside the US. The AAAS has a directorate for international programs and the authors compare the standing and objectives of the AAAS with those of equivalent societies in Europe, particularly during the nascent years of the association. It should be stressed that the book is primarily a historical account. Relatively little space is devoted to detailed descriptions of landmark publications or meeting presentations and their ensuing implications for scientific research and benefits for the quality of human life.

This book puts into perspective the values of an organization that is constantly pushing forward the boundaries of science, addressing topical issues and promoting public awareness; values that are evident in the weekly publication of its flagship magazine, Science. With the sequencing of the human genome and advent of the postgenomic era, this book represents a timely appreciation of the role that the AAAS has played, and will continue to play, in making science more accessible to all.

Andrew Aplin is in the Department of Pharmacology, University of North Carolina at Chapel Hill, North Carolina 27599, USA. e-mail:aaplin@med.unc.edu

\section{New in paperback}

Thermodynamics and Kinetics for the Biological Sciences

by Gordon G. Hammes

Wiley Interscience, £35.95/\$49.95

The Origin of Animal Body Plans: A Study in Evolutionary Developmental Biology

by Wallace Arthur

Cambridge University Press, $£ 25 / \$ 32.95$ 